\title{
LATIHAN PROPRIOSEPTIF DAN THERABAND EXERCISE LEBIH MENINGKATKAN STABILITAS DARIPADA LATIHAN PROPRIOSEPTIF DAN ANTERO POSTERIOR GLIDE PADA PEMAIN BASKET YANG MENGALAMI ANKLE SPRAIN KRONIS
}

\author{
Futi Nurul Destya ${ }^{1}$, I Made Krisna Dinata ${ }^{2}$, Wahyuddin $^{3}$, I Made Ady Wirawan ${ }^{4}$, I Dewa Ayu \\ Inten Dwi Primayanti ${ }^{2}$, Nyoman Mangku Karmaya ${ }^{5}$. \\ ${ }^{1}$ Program Studi Magister Fisiologi Keolahragaan Universitas Udayana, Denpasar \\ ${ }^{2}$ Bagian Ilmu Faal, Fakultas Kedokteran, Universitas Udayana, Denpasar \\ ${ }^{3}$ Fakultas Fisioterapi Universitas Esa Unggul, Jakarta \\ ${ }^{4}$ Ilmu Kesehatan Masyarakat, Fakultas Kedokteran, Universitas Udayana, Denpasar \\ ${ }^{5}$ Fakultas Kedokteran Universitas Udayana, Denpasar \\ E-Mail : futindestya91@gmail.com
}

\begin{abstract}
ABSTRAK
Pendahuluan: Gangguan stabilitas adalah masalah yang sering terjadi pada pasien yang terkena ankle sprain kronis. Ketidakstabilan pada ankle sprain kronik merupakan hasil dari saraf (proprioseptif, refleks, waktu reaksi otot), otot (strenght, power, dan endurance) dan mechanical mechanism (ligament laxity). Tujuan Penelitian: untuk membuktikan bahwa latihan proprioseptif dan theraband exercise lebih meningkatkan stabilitas dibanding latihan proprioseptif dan antero posterior glide pada pemain basket yang mengalami ankle sprain kronis. Metode: Penelitian ini merupakan penelitian eksperimental dengan rancangan pre dan post test control group design. Jumlah sampel penelitian 16 orang dan terbagi ke dalam dua kelompok. Kelompok I mendapat perlakuan latihan proprioseptif dan theraband exercise sedangkan Kelompok II mendapat perlakuan latihan proprioseptif dan antero posterior glide. Stabilitas diukur menggunakan Balance Error Scoring System. Hasil: Independent t-test menghasilkan $\mathrm{p}=0,000(\mathrm{p}<0,05)$. Hasil ini menunjukkan terdapat perbedaan yang bermakna antara nilai selisih sebelum dan setelah intervensi BESS pada ke dua kelompok. Simpulan: latihan proprioseptif dan theraband exercise lebih meningkatkan stabilitas dibanding latihan proprioseptif dan antero posterior glide pada pemain basket yang mengalami ankle sprain kronis
\end{abstract}

Kata kunci: Proprioseptif, Theraband Exercise, Antero Posterior Glide, Ankle Sprain Kronis.

\section{PROPRIOCEPTIVE EXERCISE AND THERABAND EXERCISE ARE BETTER ON INCREASING STABILITY THAN PROPRIOCEPTIVE EXERCISE AND ANTERO POSTERIOR GLIDE IN BASKETBALL PLAYERS WITH CHRONIC ANKLE SPRAIN}

\begin{abstract}
Background: Stability is one of major problem that often occur in chronic ankle sprain patient.

Chronic ankle instability is thought to be the result of neural (proprioception, reflexes, muscular reaction time), muscular (strength, power, and endurance), and mechanical mechanisms (ligamentous laxity). Purpose: to prove that proprioceptive exercise and theraband exercise are better on increasing stability than proprioceptive exercise and antero posterior glide in basketball
\end{abstract}


players with chronic ankle sprain. Method: This research is an experiment research design with pre and post-test control group design. Research sample included 16 people who were divided into two groups. Group I performed proprioceptive exercise and theraband exercise and group II performed proprioceptive exercise and antero posterior glide. Stability was measured by Balance Error Scoring System. Result: Independent t-test at Group 1 and Group 2 showed value $p=0.000(p<0.05)$. This result showed a significant difference between group I and II. Conclusion: proprioceptive exercise and theraband exercise are better on increasing stability than proprioceptive exercise and antero posterior glide in basketball players with chronic ankle sprain.

Keywords: Proprioceptive, Theraband Exercise, Antero Posterior Glide, Chronic Ankle Sprain.

\section{PENDAHULUAN}

Gangguan stabilitas adalah masalah besar yang sering terjadi pada populasi yang terkena ankle sprain. Data dari Poliklinik KONI Jakarta antara tahun 2009-2012 menunjukkan bahwa ankle sprain merupakan keluhan yang paling umum ditemui yang mencapai $41.1 \%$ dari seluruh kasus cedera ${ }^{1}$. Dengan persentase hingga $75 \%$ dari ankle sprain awal akan mengarah ke repetitive ankle sprain dengan sisa gejala memiliki gangguan fungsional di ankle sprain ${ }^{2}$.

Proprioseptif adalah kemampuan tubuh untuk mentransmisikan rasa posisi, menganalisis informasi itu dan bereaksi (sadar atau tidak sadar) terhadap rangsangan dengan gerakan yang tepat ${ }^{3}$. Latihan proprioseptif adalah suatu latihan yang dibentuk untuk meningkatkan proprioseptif pada ankle sprain. Mekanisme proprioseptif dalam meningkatkan stabilitas yaitu dengan proprioseptif menggambarkan sinyal aferen yang bergerak ke otak dari reseptor dalam tubuh yang memungkinkan otak untuk mengetahui di mana tubuh berada. Masukan proprioseptif diberikan ke otak melalui mechanoreceptors, reseptor vestibular dan reseptor visual. Semuanya diintegrasikan ke dalam sistem saraf pusat. Bersama-sama reseptor-reseptor ini menstimulasi respon motor eferen yang menghasilkan gerakan tubuh yang tepat ${ }^{4}$.

Theraband adalah alat atau media pembebanan untuk meningkatkan kekuatan, mobilitas, dan range of motion (ROM). Theraband exercise bertujuan untuk meningkatkan kekuatan dinamik, endurance, dan kekuatan otot dengan menggunakan tahanan yang berasal dari external force.
Theraband exercise dalam bentuk latihan isotonik dapat membantu serta memperbaiki kelemahan otot yang di sebabkan kerusakan ligamen lateral kompleks. Peningkatan kekuatan otot didapatkan dengan pelatihan secara continue sehingga kekuatan otot tonik dapat meningkatkan sirkulasi pembuluh darah kapiler yang dapat meningkatkan kekuatan otot fasik yang akan mengakibatkan terjadinya penambahan recuitment motor unit pada otot yang akan mengaktivasi badan golgi sehingga otot akan bekerja secara optimal, sehingga terbentuk stabilitas yang baik pada ankle .

Antero posterior glide merupakan salah satu teknik mobilisasi sendi. Mobilisasi sendi adalah teknik manual terapi yang terdiri dari rangkaian kemampuan gerak pasif dari suatu sendi atau jaringan lunak (atau ke duanya) yang digerakkan dengan kecepatan dan amplitudo yang bervariasi. Mobilisasi sendi bertujuan untuk meningkatkan gerakan fisiologis dan aksesori melalui peningkatan kemampuan ekstensibilitas jaringan kapsuler dan ligamen nonkontraktil dan meningkatkan transmisi informasi aferen dengan merangsang sendi mechanoreceptors ${ }^{6}$.

Berdasarkan pemaparan tersebut, disimpulkan bahwa pemberian proprioseptif dan theraband exercise akan membantu otot bekerja dengan maksimal sehingga dapat meningkatkan stabilitas yang baik, sedangkan proprioseptif dan anteroposterior glide akan merangsang sendi mechanoreceptor untuk menjaga posisi tubuh saat statis dan dinamis. Ke dua latihan tersebut memiliki target yang berbeda untuk membentuk stabilitas pada ankle sprain. 


\section{METODE PENELITIAN}

Rancangan penelitian adalah eksperimental dengan Kelompok I diberikan proprioseptif dan theraband exercise dan Kelompok II diberikan proprioseptif dan antero posterior glide. Pengukuran stabilitas diukur menggunakan Balance error Scoring System (BESS).

Penelitian ini dilakukan di SMP 2 Garut Jawa Barat, pada Maret - April 2019. Penelitian dilakukan dengan frekuensi 3 kali seminggu yang berlangsung selama 6 minggu. Sampel berjumlah 8 orang di masing-masing kelompok, yang diseleksi dari populasi ankle sprain di SMP 2 Garut dengan kriteria inklusif laki-laki dan perempuan berusia 1218 tahun, anterior drawer test atau tilting test positif, fase kronis lebih dari 7 hari pasca cedera dapat berkomunikasi dengan baik, kooperatif dan bersedia mengikuti penelitian. Kriteria eksklusi pada penelitian ini adalah adanya riwayat operasi sebelumnya terlebih pada ekstremitas bagian bawah, pernah atau sedang melakukan fisioterapi untuk ankle sprain, adanya riwayat patah tulang dan cedera akut pada sendi lain muskuloskeletal terutama ekstremitas bawah.

\section{HASIL PENELITIAN}

\section{Karakteristik Subyek}

Berdasarkan Tabel 1 menunjukkan bahwa pada karakteristik jenis kelamin, umur, dan IMT nilai $\mathrm{p}>0,05$. Data tersebut menunjukkan bahwa untuk seluruh karakteristik sampel antara ke dua kelompok memiliki karakteristik yang tidak berbeda.

Tabel 1.

Karakteristik Sampel

\begin{tabular}{|c|c|c|c|c|}
\hline \multirow[b]{2}{*}{ Karakteristik } & \multirow[b]{2}{*}{ Kategori } & \multicolumn{2}{|c|}{ Frekuensi } & \multirow[b]{2}{*}{$p$-value $e^{\mathrm{a}}$} \\
\hline & & Kelompok I & $\begin{array}{c}\text { Kelompok } \\
\text { II }\end{array}$ & \\
\hline \multicolumn{2}{|c|}{ Jenis Kelamin Laki-laki } & $4(50 \%)$ & $5(62,5 \%)$ & \multirow{3}{*}{0,614} \\
\hline \multirow{4}{*}{$\begin{array}{c}\text { Usia } \\
\text { (tahun) }\end{array}$} & Perempuan & $4(50 \%)$ & $3(37,5 \%)$ & \\
\hline & Total & $8(100 \%)$ & $8(100 \%)$ & \\
\hline & 12-13 tahun & $3(37,5 \%)$ & $1(12,5 \%)$ & \multirow{2}{*}{0,475} \\
\hline & 14-15 tahun & $3(37,5 \%)$ & $5(62,5 \%)$ & \\
\hline
\end{tabular}

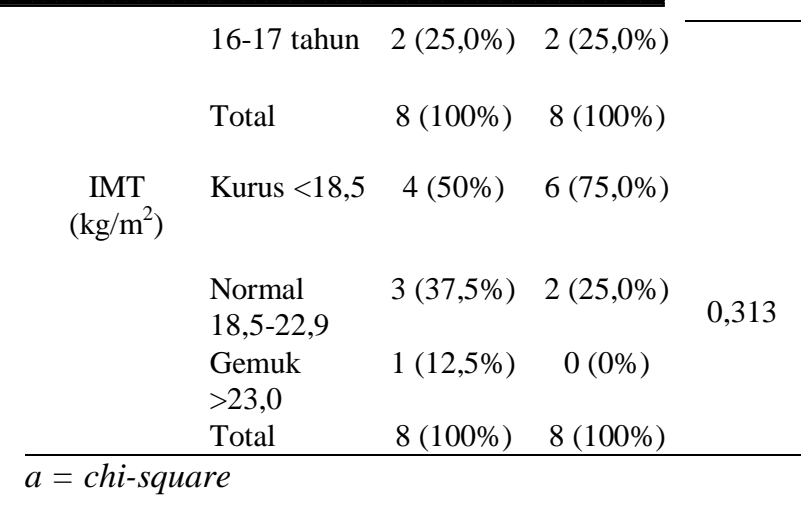

\section{Uji Normalitas dan Homogenitas}

Berdasarkan Tabel 2 keseluruhan data memiliki nilai $\mathrm{p}>0,05$ dan menunjukkan seluruh data pada masing-masing kelompok memiliki berdistribusi normal. Sehingga uji hipotesis yang digunakan adalah parametrik. Uji homogenitas didapatkan nilai $\mathrm{p}=0,710$ ( $\mathrm{p}$ $>0,05$ ) yang menunjukkan data homogen pada sebelum pelatihan.

Tabel 2.

Hasil Uji Normalitas dan Homogenitas

\begin{tabular}{cccc}
\hline Grup & \multicolumn{2}{c}{ Uji Normalitas } & Sebelum \\
$\mathrm{P}^{\mathrm{a}}$ & $\begin{array}{c}\text { Sesudah } \\
\mathrm{P}^{\mathrm{a}}\end{array}$ & $\begin{array}{c}\text { Uji Homogenitas } \\
\mathrm{P}^{\mathrm{b}}\end{array}$ \\
\hline I & 0,605 & 0,067 & 0,710 \\
II & 0,242 & 0,128 & \\
\hline
\end{tabular}

$\mathrm{a}=$ Shapiro-wilk test

$\mathrm{b}=$ Leuvene test

\section{Uji Beda Nilai BESS Sebelum dan Setelah Perlakuan di Kelompok I dan Kelompok II}

Berdasarkan data pada Tabel 3 diperoleh nilai $\mathrm{p}=0,001 \quad(\mathrm{p}<0,05)$ pada Kelompok 1 yang menunjukkan adanya peningkatan pada stabilitas ankle setelah pemberian latihan proprioseptif dan theraband exercise. Pada Kelompok 2 nilai $\mathrm{p}$ $=0,001(\mathrm{p}<0,05)$ yang menunjukkan adanya peningkatan pada stabilitas ankle setelah pemberian latihan proprioseptif dan antero posterior glide.

Tabel 3.

Hasil Uji Beda Nilai BESS Sebelum dan Setelah Perlakuan Pada Kelompok I dan II 


\begin{tabular}{cccc}
\hline \hline & Sebelum & Setelah & \\
\cline { 2 - 3 } Kelompok & & & \\
\cline { 2 - 3 } & Rerata \pm -SD & Rerata \pm SD & \\
\hline I & $31,25 \pm 5,20$ & $3,25 \pm 1,66$ & 0,001 \\
II & $29,75 \pm 4,26$ & $11,87 \pm 2,10$ & 0,001 \\
-value $^{\mathrm{b}}$ & 0,539 & 0,001 & \\
\hline
\end{tabular}

$\mathrm{a}=$ dependen sampel t-test

$\mathrm{b}=$ independen sampel $\mathrm{t}$-test

\section{Uji Beda Selisih BESS Setelah Perlakuan Pada Kelompok I dan II}

Berdasarkan Tabel 4 menunjukkan bahwa pada data sesudah pelatihan nilai $\mathrm{p}=$ $0,001(\mathrm{p}<0,05)$. Hal ini menunjukkan adanya perbedaan yang signifikan pada Kelompok 1 dan Kelompok 2. Nilai rerata selisih perlakuan pada Kelompok I yaitu 28,00 \pm 4,34. Sedangkan pada Kelompok II didapatkan nilai selisih yaitu $17,87 \pm 2,90$. Berdasarkan hasil tersebut, rerata selisih pada Kelompok I lebih besar dari rerata setelah di Kelompok II, dapat disimpulkan bahwa perlakuan di Kelompok I mengalami peningkatan stabilitas yang lebih baik.

Tabel 4.

\begin{tabular}{ccc}
\hline Kelompok & Mean \pm SD & p-value $^{\mathrm{a}}$ \\
\cline { 2 - 2 } & & \\
\hline Perlakuan 1 & $28,00 \pm 4,34$ & 0,001 \\
Perlakuan II & $17,87 \pm 2,90$ & \\
\hline
\end{tabular}

$\mathrm{a}=$ independen sampel $\mathrm{t}$-test

\section{PEMBAHASAN}

\section{Latihan Proprioseptif dan Theraband Exercise dapat Meningkatkan Stabilitas pada Pemain Basket yang Mengalami Ankle Sprain Kronis}

Berdasarkan beberapa kajian teori dan penelitian sebelumnya latihan proprioseptif berpengaruh pada beberapa hal pada ankle sprain kronik karena terjadinya penurunan dari pada fungsi proprioseptif ${ }^{7}$. Pelatihan dengan wobble board dapat mengembalikan fungsi dari proprioseptif melalui serabut saraf aferen akan membawa respon ke sistem saraf pusat (SSP) yang berperan untuk mempertahankan keseimbangan tubuh tetap dengan posisi stabil. Prinsip dari latihan ini untuk meningkatkan fungsi dari pengontrol keseimbangan tubuh. Saat latihan berlangsung rangsangan yang diterima serabut intrafusal dan ekstrafusal memperkaya input sensoris yang akan dikirim dan diolah di otak untuk diproses sehingga dapat menentukan seberapa besar kontraksi otot yang dapat diberikan. Sebagian respon yang dikirim kembali ke ekstrafusal akan mengaktivasi golgi tendon kemudian akan terjadi perbaikan koordinasi serabut intrafusal (myofibril) dan serabut ekstrafusal (golgi tendon organ) dengan saraf aferen yang ada di muscle spindle sehingga terbentuklah proprioceptive yang baik ${ }^{8}$.

Intervensi theraband exercise yang diberikan untuk meningkatkan stabilitas pada kondisi ankle sprain kronik akibat dari adanya overstretch dari ligamen akibat menumpu maka posisi ligamen akan cenderung terulur dan menyebabkan instabilitas pada ligamen sehingga otot-otot lain akan bekerja secara berlebihan untuk menstabilkan sendi ankle, dengan latihan proprioseptif dan theraband exercise maka otot ankle yang termasuk tipe otot tonik (antagonis) dapat meningkatkan sirkulasi pembuluh darah kapiler sehingga akan meningkatkan kekuatan otot, sedangkan kekuatan otot agonis akan mengakibatkan terjadinya peningkatan recruitment motor unit pada otot yang akan mengaktivasi badan golgi, sehingga otot akan bekerja secara optimal yang terdepolarisasi selama latihan, dengan banyaknya motor unit yang terdepolarisasi akan menghasilkan kekuatan yang besar. Latihan yang benar dan teratur akan meningkatkan kekuatan otot-otot stabilisator pada ankle ${ }^{9}$

\section{Latihan Proprioseptif dan Antero Posterior Glide dapat Meningkatkan Stabilitas pada Pemain Basket yang Mengalami Ankle Sprain Kronis}

Berdasarkan beberapa kajian teori dan penelitian sebelumnya bahwa pelatihan proprioceptive dengan wobble board merupakan latihan stabilisasi dinamik pada posisi tubuh statis yaitu kemampuan tubuh untuk menjaga stabilisasi pada posisi tetap 
dengan cara berdiri satu atau dua kaki di atas wobble board. Prinsip dari latihan ini ialah meningkatkan fungsi dari pengontrol keseimbangan tubuh yaitu sistem informasi sensoris, central processing, dan efektor untuk bisa beradaptasi dengan perubahan lingkungan. Saat latihan berlangsung rangsangan yang diterima serabut intrafusal dan ekstrafusal memperkaya input sensoris yang akan dikirim dan diolah di otak untuk diproses sehingga dapat menentukan seberapa besar kontraksi otot yang dapat diberikan. Sebagian respon yang dikirim kembali ke ekstrafusal akan mengaktivasi golgi tendon kemudian akan terjadi perbaikan koordinasi serabut intrafusal (myofibril) dan serabut ekstrafusal (golgi tendon organ) dengan saraf aferen yang ada di muscle spindle sehingga terbentuklah proprioceptive yang baik ${ }^{8,10}$. Stimulasi yang tidak konsisten akibat ketidakstabilan permukaan yang diterima oleh otot dan sendi berpengaruh sangat cepat terhadap penangkapan informasi sensoris dan lebih efisien diproses di sistem saraf pusat sehingga menstimulasi mekanoreseptor pada sendi ${ }^{10}$.

Mobilisasi sendi antero posterior glide juga meningkatkan transmisi informasi aferen dengan stimulasi sensoreceptor sendi. Metode ini secara konsisten mampu untuk meningkatkan ROM dorsal fleksi dan posterior talar glide pada individu dengan ankle sprain akut atau kronis. Menggabungkan peningkatan aktivitas aferen dan peningkatan fungsi neuromuskuler otot penstabil sendi memungkinkan peningkatan kontrol postural dengan menggunakan mobilisasi sendi. Pemeriksaan dari efek mobilisasi sendi pada kontrol postural dinamis memungkinkan untuk memahami kemampuannya untuk meningkatkan fungsi sistem sensorimotor ankle sprain kronik yang tidak stabil ${ }^{11}$.

\section{Latihan Proprioseptif dan Theraband Exercise Lebih Meningkatkan Stabilitas daripada Latihan Proprioseptif dan Antero Posterior Glide pada Pemain Basket yang Mengalami Ankle Sprain Kronis}

Berdasarkan beberapa kajian teori dan penelitian sebelumnya yang menyatakan bahwa latihan kekuatan otot dengan menggunakan proprioseptif dan theraband dapat meningkatkan perkembangan otot dan meningkatkan kontrol neuromuskuler juga telah dilaporkan mempengaruhi perekrutan unit motorik, aktivasi selektif dari otot agonis dan unit motoriknya, dan koaktivasi antagonis. Pelatihan kekuatan enam minggu secara progresif menggunakan theraband menghasilkan peningkatan baik dalam arti kekuatan dan posisi sendi di ankle. Peningkatan yang terjadi dikaitkan dengan sensitivitas spindle otot dan aktivasi aferen hal ini menunjukkan bahwa dengan kekuatan menggunakan theraband efektif meningkatkan langkah-langkah proprioseptif dari keseimbangan ${ }^{12}$.

Latihan theraband dapat meningkatkan kekuatan yang menghasilkan peningkatan aktivasi gamma-eferen. Spindel menjadi lebih sensitif terhadap peregangan seketika, menghasilkan ketajaman yang lebih besar dalam merasakan posisi sendi, juga eferensia gamma yang dinamis meningkatkan kepekaan terhadap laju perubahan panjang. Theraband elastis telah terbukti dapat meningkatkan kekuatan, mobilitas, dan fungsi serta mengurangi nyeri sendi. Sejumlah literatur menunjukkan keuntungan dari awal, dengan menggunakan theraband exercise dapat membantu dalam meningkatkan ROM, menurunkan nyeri, penghambatan saraf, otot lebih cepat berfungsi ${ }^{13}$.

Pencegahan cedera ankle sprain kronis diperlukan pelatihan khusus untuk menghindari terjadinya cedera ulang karena secara umum cedera yang terjadi pada ankle adalah sprain. Melalui pelatihan proprioceptive dan pelatihan penguatan otot ankle dengan karet elastic resistance maka keseimbangan dan kontrol neuromuskuler akan membaik sehingga terjadi penurunan 
foot and ankle disability dengan kembalinya efisiensi gerakan dan aktivitas normal ${ }^{14,15}$.

Mobilisasi sendi antero posterior gliding yang diberikan berupa terapi manipulasi memiliki efek pada struktur sendi dan jaringan, yaitu efek fisik, merangsang aktivitas biologis di dalam sendi melalui gerakan cairan sinovial. Gerakan cairan sinovial dapat meningkatkan proses pertukaran nutrisi ke permukaan kartilago sendi dan fibrokartilago. Efek stretching akan mengulur kapsul ligamen melalui pelepasan abnormal cross link antara serabut-serabut kolagen atau jaringan fibrous akan berkurang dan meningkatkan elastisitas, fleksibilitas pada otot dan jaringan lainnya sehingga akan terjadi perbaikan lingkup gerak sendi yang maksimal $^{16}$.

Terapi manual telah dikaitkan dengan perubahan aktivitas otot (muscle reflexogenic) dan motoneuron pool activity. Secara definisi, muscle reflexogenic merupakan perubahan penurunan hipertonisitas otot-otot. Dorongan yang terjadi selama manipulasi atau gaya osilasi berulang digunakan selama mobilisasi untuk mengurangi rasa sakit melalui induksi penghambatan refleks otot tegang. Penghambatan otot reflexogenic adalah konsekuensi dari rangsangan pada kulit, otot, dan reseptor sendi artikular. Peran utama kulit, otot, dan sendi artikular mechanoreceptors adalah untuk mendeteksi kehadiran gerakan atau masukan energi dan memberikan saraf pusat sistem dengan informasi proprioseptif atau nosiseptif. Lokasi dan desain mechanoreceptor menguraikan peran yang dimainkannya dalam proprioseptif $^{17}$.

Sebuah studi oleh Pellow dan Bratingham mempelajari efek dari terapi manipulasi talocrural anterior posterior glide pada keterbatasan ROM dorsofleksi, nyeri dan skor fungsional dihasilkan pada follow-up satu bulan peneliti menemukan perubahan signifikan pada area kaki dalam perawatan kelompok menunjukkan stabilitas yang baik ${ }^{18}$. Penelitian sebelumnya oleh Weerasekara et al pada tahun 2018 berupa systematic review dan meta analisis tentang mobilisasi sendi pada ankle sprain didapatkan hasil bahwa mobilisasi sendi dapat meningkatkan keseimbangan dinamik dan juga penambahan ROM dalam jangka pendek, pada jangka panjang belum diinvestigasi secara memadai ${ }^{19}$.

\section{KETERBATASAN PENELITIAN}

Dalam pengambilan data tidak dilakukan randomisasi karena kesulitan dalam mengontrol subjek yang masih remaja.

\section{SIMPULAN}

1. Latihan proprioseptif dan theraband exercise dapat meningkatkan stabilitas pada pemain basket yang mengalami ankle sprain kronis.

2. Latihan proprioseptif dan antero posterior glide dapat meningkatkan stabilitas pada pemain basket yang mengalami ankle sprain kronis.

3. Latihan proprioseptif dan theraband exercise lebih meningkatkan stabilitas daripada latihan proprioseptif dan antero posterior glide pada pemain basket yang mengalami ankle sprain kronis.

\section{DAFTAR PUSTAKA}

1. Marta, K.K.A., Kawiyana, I.K.S. 2016. Management of Acute Ankle Sprain: Literatur Review. Indonesia Journal of Biomedical Science, Vol 2: 20-26.

2. Hubbard, T.J., Wikstrom, E.A. 2010. Ankle sprain: pathophysiology, predisposing factors, and management strategies. J Sports Med, Vol 1: 115122.

3. Houglum, P.A. 2005. Therapeutic Exercise for Musculoskeletal Injuries (2nd edition). Champaign, IL: Human Kinetics.

4. Akre, A., Kumaresan, K. 2014. Comparison of a strengthening programme to a proprioceptive training in improving dynamic balance in athletes with chronic ankle instability ( CAI ). IOSR Journal of Sports and Physical Education (IOSR-JSPE), Vol 1 No.5: 18-20. 
5. O’Driscoll, J., Delahunt, E. 2011. Neuromuscular training to enhance sensorimotor and functional deficits in subjects with chronic ankle instability: A systematic review and best evidence synthesis. Sports Medicine, Arthroscopy, Rehabilitation, Therapy and Technology, Vol 3: 19.

6. Wells, A.M. 2012. Effects of Joint Mobilization on Ankle Dorsiflexion Range of Motion, Dynamic Postural Control and Self-Reported Patient Outcomes in Individuals with Chronic Ankle Instability. The University of Toledo.

7. Sherwood, L. 2009. Fisiologi Manusia dari Sel ke Sistem (Edisi VI). Jakarta: EGC.

8. Miller, J. 2011. Proprioceptive Training and Its Implications on Ankle Rehabilitation. Journal of Athletic Training, Vol 5: 163-170.

9. Bracker, M.D., Achar, S.A. 2011. The 5-minute Sports Medicine Consult. Philadelphia, Unites States: Lippincott Williams and Wilkins.

10. Hupperets, M.D., Verhagen, E.A., Mechelen, W.V. 2009. Effect of unsupervised home based proprioceptive training on recurrences of ankle sprain: randomised controlled trial. $B M J, 339$ : b2684.

11. Hoch, M.C., Mckeon, P.O. 2010. The Effectiveness of Mobilization With Movement at Improving Dorsiflexion After Ankle Sprain. J Sport Rehabil, Vo 19 No.2: 226-232.

12. Smith, B.I., Docherty, C., Simon, J., Klossner, J., Schrader, J. 2012. Ankle Strength and Force Sense After a Progressive, 6-Week Strength-Training Program in People With Functional Ankle Instability. J Athl Train, Vol 47 No.3: 283-288.

13. Babu, G.H., Ravindran, B., Kiran, V., Kumar, K.A., Reddy, S.K., Subbiah, K. 2017. The Effectiveness of Mobilization and Thera band Exercises for Ankle Sprain. Jurnal Of Medical Science And Clinical Resarch, Vol 05 No.6: 2321323218
14. Hyeyoung, K., Enjung, C., Lee, B. 2013. A Comparison of the Foot and Ankle Condition between Elite Athletes and Non-athletes. Journal of Physical Therapy Science, Vol 25 No.10: 12691272.

15. Muawanah, S. 2015. Perbedaan Pelatihan Proprioceptive Menggunakan Wobble Board dengan Pelatihan Penguatan Otot Ankle Menggunakan Karet Elastic Resistance Dalam Menurunkan Foot and Ankle Disability. Sport and Fitness Journal, Vol 4 No.1: 59-71.

16. Edmond, S. 2006. Techniques Joint Mobilization/manipulation, Extremity and Spinal (Second). St. Louis : Mosby Elsevier.

17. Cook, C.E. 2012. Orthopedic Manual Therapy (2nd edition). Walsh University: Pearson.

18. Loudon, J.K., Reiman, M.P., Sylvain, J. 2014. The efficacy of manual joint mobilisation/manipulation in treatment of lateral ankle sprains: a systematic review. Br J Sports Med: 365-370.

19. Weerasekara, I., Osmotherly, P., Snodgrass, S., Marquez, J., Zoete, R.D., Rivvet, D.A., 2018. Clinical Benefits of Joint Mobilization on Ankle Sprains. A systematic Review and Meta Analysis. Physical Medicine and Rehabilitation, Vol 99 No.7: 1395-1412. 